\title{
POSSIBILITIES OF HEAT TRANSFER AUGMENTATION IN HEAT EXCHANGERS WITH MINICHANNELS FOR MARINE APPLICATIONS
}

\author{
Dariusz Mikielewicz \\ Jan Wajs \\ Gdansk University of Technology, Poland
}

\begin{abstract}
In the paper, new trends in the development of microchannel heat exchangers are presented. The exchangers developed in this way can be applied in marine industry. Main attention is focused on heat exchanger design with reduced size of passages, namely based on microchannels. In authors' opinion, future development of high power heat exchangers will be based on networks of micro heat exchangers.
\end{abstract}

Keywords: heat transfer intensification, heat exchangers, pumping power

\section{INTRODUCTION}

The weight of the equipment onboard a ship and the space requirements are nowadays more important than ever, therefore selection of the right equipment and its size is of high importance [1]. When investing in new heat exchangers for today's vessels, ship owners, operators, and shipyards are looking for ways to reduce costs, boost the performance of the applied systems, and meet energy efficiency and emission requirements of contemporary stringent standards. Recent technological advances contribute to improved performance, greater reliability, and lower lifecycle costs, all this having a positive impact on profitability. A typical heat exchanger design strategy is to obtain a high heat transfer rate using minimum pumping power and space. When the fluid with low thermal conductivity passes through the heat exchanger, there is a necessity to increase the heat transfer rate but in some of applications, in marine and chemical industries for instance, the resistance to heat transfer increases cause to fouling or scaling.

Most cooling systems are made as central cooling systems, which means that there is only one or two large plate heat exchangers equipped with titanium plates, which come into contact with the seawater. Titanium is the only material that can withstand the aggressive seawater without corrosion damages on the plates in the heat exchanger. Some analyses of that issue are presented in $[2,3]$. It should be borne in mind that titanium is relatively expensive and therefore efforts must be made to use it responsibly. This means that the central cooler can operate without problems using seawater as the cooling medium for the internal freshwater cooling system. The advantage of the central cooler is that the use of the corrosive seawater is limited to one or two plate heat exchangers, and thereby the use of the expensive material for that exchanger and the seawater pipeline is limited to a minimum, which will reduce the corrosion damage in the cooling system. The remaining plate heat exchangers are normally equipped with stainless steel plates, for which there is no corrosion risk as the heat exchangers work with freshwater. In future applications, some effort should be made to use plastics [4-6], which do not exhibit susceptibility to corrosion and are much cheaper.

Heat transfer enhancement or augmentation techniques refer to the improvement of thermo-hydraulic performance of heat exchangers. Among many techniques (both passive and active) investigated for augmentation of heat transfer rates inside circular tubes, a wide range of inserts have been utilized, particularly when turbulent flow is considered [7]. A lot of methods, such as treated surfaces, porous surfaces [8], rough surfaces [9], swirling flow devices, coiled tubes, and surface tension devices have been applied to increase thermal performance of heat transfer devices. Furthermore, as a heat exchanger becomes older, the resistance to heat transfer increases owing to fouling or scaling. These problems are more 
common for heat exchangers used in marine applications than in other areas. In some specific applications, such as heat exchangers dealing with low thermal conductivity fluids (gases and oils) and desalination plants, there is a need to increase the heat transfer rate [10]. It can be improved by introducing a disturbance in the fluid flow (breaking the viscous and thermal boundary layers), but in that case the process pumping power may increase significantly and ultimately the pumping cost may become unacceptably high. Therefore, to achieve a desired heat transfer rate in the existing heat exchanger at an economical pumping power, several techniques have been proposed in recent years and are discussed in the following sections.

For many years, the authors have been conducting investigations regarding the methods of heat transfer enhancement to improve the performance of heat exchangers. In this paper, a new design of plate heat exchanger with minichannels (MPHE) is proposed. The experimental analysis of the prototype is described.

\section{CRITERION FOR COMPARISON OF HEAT INTENSIFICATION EFFECT}

A useful method of comparing the performance of smooth tubes and the tubes with modified surfaces for the purpose of intensification of heat transfer is to compare them at equal pumping power. That is expressed by the equation:

$$
(\dot{V} \Delta p)_{0}=(\dot{V} \Delta p)
$$

Expressing adequately the volumetric flow rate and the pressure drop we get the relation between the resistance coefficient and the Reynolds number:

$$
(\dot{V} \Delta p)_{0}=(\dot{V} \Delta p)
$$

The heat transfer intensification coefficient can be defined as a function of heat transfer efficiency increase and pumping power at the same flow rate. This parameter is also used for comparisons between various passive heat transfer intensification techniques at specified pressure drop. It is described by an equation arising from Equation (2), [7]:

$$
E=\frac{\left(N u / N u_{0}\right)}{\left(f / f_{0}\right)^{1 / 3}}
$$

where $N u, f, N u_{0}$ and $f_{0}$ are the Nusselt numbers and resistance coefficients, respectively, for two channel configurations, i.e. with and without the turbulising insert. The resistance coefficient is determined based on the pressure drop or on the power of the pump. The intensification efficiency (at constant pumping power) can be expressed as [7]:

$$
E_{p}=\left.\frac{\alpha}{\alpha_{0}}\right|_{\text {pumpingpower }=\text { const }}
$$

Expressions (4) or (5) can be rather used only for singlephase flows, as the correlations describing the relation between the heat transfer coefficient and the Reynolds number, and between the resistance coefficient and the Reynolds number are required simultaneously. Finding such correlations for flow boiling is very difficult, or even impossible in some circumstances. In that case the heat transfer intensification is expressed as the heat transferred through the tube in relation to the pumping power for both cases: smooth and turbulised tube. Such a methodology is possible and the expression (4) is based on it.

Heat transfer intensification in the channel with flow boiling can be described as the ratio of the heat absorbed by the tube to the pumping power, firstly for the tube with a turbulising insert, and then for the smooth tube of the same diameter, subscript 0 , respectively. This method can be used when the qualities in both cases are equal. The expression is [7]:

$$
E_{x}=\left.\frac{\left(\frac{\dot{Q}}{\dot{V} \Delta p}\right)}{\left(\frac{\dot{Q}}{\dot{V} \Delta p}\right)}\right|_{x=\text { const }}
$$

If $E_{x}>1$, the intensification occurs in the examined configuration. Equation (5) is the general expression. The numerator can be interpreted as the net heat which can be transferred through the channel with intensification. The denominator describes the same for the smooth tube. The compared net effect includes both the quantity of the transferred heat and the expenditure of energy needed for medium pumping.

An idea of novel plate heat exchanger with minichannels is presented together with thermal-hydraulic characteristics of its prototype. This kind of heat exchangers can be prospectively applied in marine systems, but other applications are also possible. A simplified routine is presented for design of micro heat exchangers, such as evaporator or condenser for instance, with account of pressure drops in the heat exchanger. Moreover, the comparison analysis between different models for calculation of two-phase pressure drop in small diameter tubes is also included. As a result of the here presented calculations, real heat exchangers with small dimensions have been obtained.

\section{IMPACT OF HYDRAULIC DIAMETER OF MICROCHANNELS ON HEAT EXCHANGER SIZE}

A common way to increase the heat transfer coefficient ( $a$ in Eq. (6a)) is to reduce the hydraulic diameter $\left(d_{h}\right)$ of the channel. Usually, the laminar flow conditions should be applied for heat exchange in minichannels as the pressure drop becomes excessively high. For the laminar flow, such as 
that taking place in micro- and minichannels, the value of the Nusselt number is constant. The rate of heat density, which is the ratio of heat transfer rate to heat exchanger volume, is:

$$
\frac{\dot{Q}}{V}=\frac{U \cdot \Delta T \cdot A}{V},
$$

where:

$$
A=n \cdot \pi \cdot d_{h} \cdot L, \quad V=2 \cdot n \cdot \pi \cdot \frac{d_{h}^{2}}{4} \cdot L, \quad U=\frac{1}{1 / \alpha_{1}+1 / \alpha_{2}} \approx \frac{\alpha}{2}=\frac{\lambda \cdot N u}{2 \cdot d_{h}}
$$

As can be concluded from Equation (6), the rate of heat density is inversely proportional to the hydraulic diameter of the channel:

$$
\frac{\dot{Q}}{V}=\propto \frac{1}{d_{h}^{2}} .
$$

The lower the hydraulic diameter of the minichannels in the heat exchanger, the higher the rate of heat transfer density.

A few methods exist to increase the heat transfer coefficient in microchannels. One of them, presented above, is to reduce the hydraulic diameter of the microchannels. Another method takes advantage of the fact that the developing flow has a higher heat transfer coefficient than the fully developed flow, what is schematically presented in Fig. 1. Hence short micro channels of the length shorter than the thermal entrance region should be applied to increase the heat transfer coefficient.

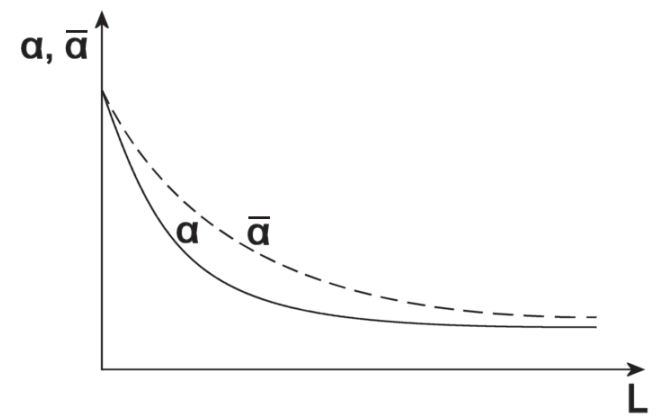

Fig. 1. Change of local and mean heat transfer coefficient along the pipe

Other methods base on the use of corrugated or rough minichannels.

\section{MINICHANNEL PLATE HEAT EXCHANGER}

Concepts to reduce the channel hydraulic diameter, together with the attempt to break-up the thermal boundary layer, have been applied in the present work. Figure 2 shows the prototype plate heat exchanger with minichannels (MPHE). It consists of a series of gasketed brazed plates with channels of rectangular cross-section (width $a=1 \mathrm{~mm}$, depth $b=700 \mu \mathrm{m}$ ) and of $40 \mathrm{~mm}$ in length. The distance between the channels is equal to $1 \mathrm{~mm}$, and the heat transfer area is equal to $0.00694 \mathrm{~m}^{2}$. Three types of heat transfer enhancement methods were tested:

1) Version I - heat exchanger with unmodified minichannels,

2) Version II - heat exchanger with minichannels cut perpendicularly to the flow direction,

3) Version III - heat exchanger with minichannels cut at the angle of 60 degrees.

The analysis was conducted on the model of heat exchanger consisting of one hot and one cold passage, Fig. 2. Such an arrangement was selected to get better insight into heat transfer and pressure drop in the novel construction. During the first stage of the experiment the heating fluid (hot water) prepared by the electric heater was circulating in the system, while the cold water was a tap water. The heat was transferred in the counter-current flow of working fluids. In the second round of the experiment, the heating fluid was water whereas ethanol was the heated medium.

During the experiments the following parameters were measured: the hot fluid temperature at the inlet $\left(T_{h-i n}\right)$ and outlet $\left(T_{\text {h-out }}\right)$ of the heat exchanger, the cold fluid temperature at the inlet $\left(T_{c-\text { in }}\right)$ and outlet $\left(T_{c-\text { out }}\right)$ of the heat exchanger, the pressure drops connected with the fluid flow $\left(\Delta P_{\text {exp }}\right)$, the volumetric flow rate of hot water, and the volumetric/mass flow rate of the working fluid. The measured values of these parameters made the basis for calculating the heat flux (q), the Logarithmic Mean Temperature Difference (LMTD) in the heat exchanger, and the overall heat transfer coefficient $(U)$. The overall heat transfer coefficient was determined with the aid of the Peclet law based on the heat transfer area and the average value of the heat rate transferred through the wall in a given measurement series.
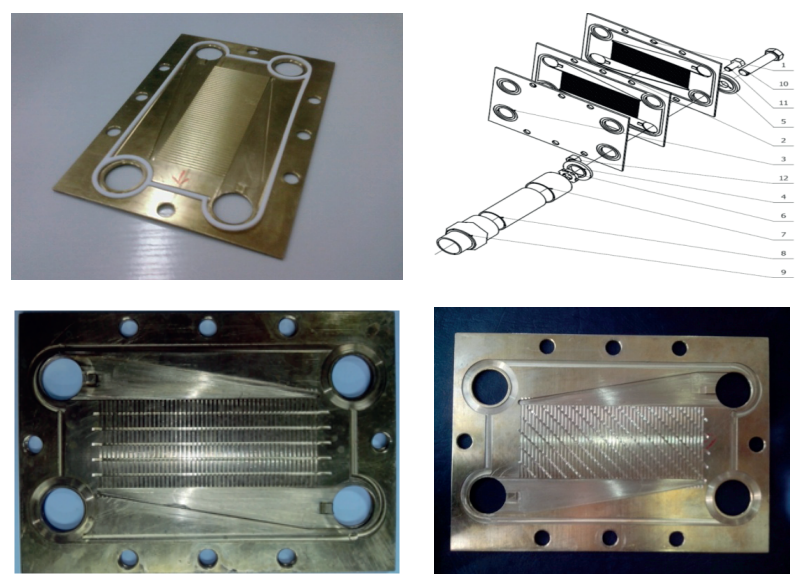

Fig. 2. Minichannel heat exchanger and view of plates with minichannels of different types.

\section{EXPERIMENTAL FACILITY}

A schematic of the experimental facility is presented in Fig. 3. The volumetric flow rate of water $\left(\dot{V}_{w}\right)$ was measured by rotameter V31 (by Heinrichs). Its measurement range was from $50 \mathrm{l} / \mathrm{h}$ to $500 \mathrm{l} / \mathrm{h}$ and its accuracy class was 1 . The ethanol volume flow rate $\left(V_{e t}\right)$ was measured by a calibrated 
rotameter. In the single-phase flow experiments in waterwater configuration the volumetric flow rates of hot and cold water were varied in the same range, from 50 to $400 \mathrm{l} / \mathrm{h}$. The temperature of the hot water entering the heat exchanger was $92^{\circ} \mathrm{C}$, whereas the cold water temperature was equal to $7^{\circ} \mathrm{C}$ in each measurement series. In the single-phase flow experiments in water-ethanol configuration the volumetric flow rate of hot water was varied in the range from 50 to $125 \mathrm{l} / \mathrm{h}$, while the ethanol flow rate was varied in the range from 26 to $78 \mathrm{l} / \mathrm{h}$. The temperature of the hot water supplying the heat exchanger was $80^{\circ} \mathrm{C}$, whereas the ethanol temperature was equal to $30 \pm 0.5^{\circ} \mathrm{C}$ in each measurement series.

In the case of flow boiling, the volumetric flow rate of hot water varied in the range from 125 to $175 \mathrm{l} / \mathrm{h}$ (which corresponds to the water mass flux $G_{W}$ ranging from 972 to $1360 \mathrm{~kg} /\left(\mathrm{m}^{2} \mathrm{~s}\right)$ in a single rectangular channel), while the ethanol flow rate varied in the range from 14 to $22 \mathrm{l} / \mathrm{h}$ (which corresponds to the range of ethanol mass flux $G_{e t}$ from 47 to $102 \mathrm{~kg} /\left(\mathrm{m}^{2} \mathrm{~s}\right)$ in a single rectangular channel). The temperature of the hot water supplying the heat exchanger was in the range 91- $100.5^{\circ} \mathrm{C}$, whereas the temperature of the ethanol entering the heat exchanger was about $80^{\circ} \mathrm{C}$.

In the boiling flow experiments the ethanol was preliminarily heated to make the boiling heat transfer inside the heat exchanger the most effective. It was delivered to the heat exchanger with subcooling of $3 \mathrm{~K}$ in relation to its saturation temperature controlled by an ultra-thermostat. It means that the flow rate measurements were done when the ethanol had temperature near the saturation state and was still in the liquid state. The flow of water was first directed to the rotameter and then to the electric heater to obtain the required parameters at heat exchanger inlet. The heater was controlled by an autotransformer, which allowed smooth adjustment of heater power and then precise water temperature setting. The ethanol was circulating in a closed system equipped with a thermostatic bath, which heated it to a certain level before it entered the heat exchanger. For the needs of the experiment, an additional heat exchanger supplied with the tap (cold) water was provided to the thermostatic bath. It was used to withdraw from the ethanol the thermal energy gained by it, thus assuring the stationary state of the analysis.

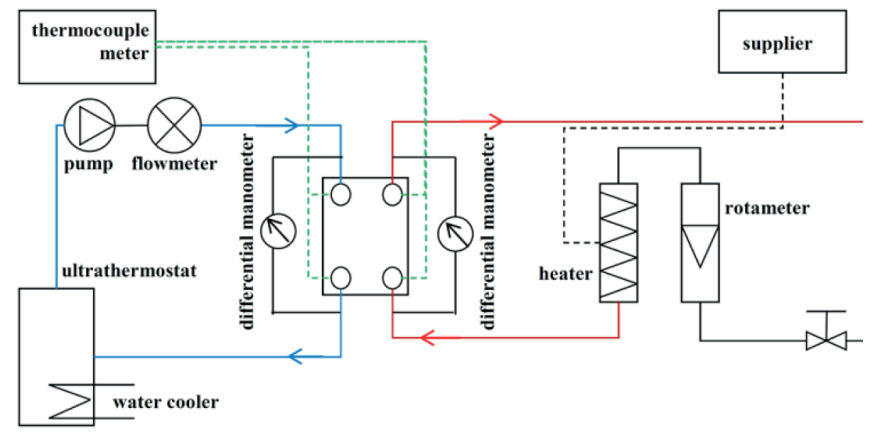

Fig. 3. Scheme of experimental facility

\section{SINGLE-PHASE FLOW DATA}

Pressure changes as a function of the volumetric flow rate are presented in Fig. 4 . The curve exhibits an exponential character. Relatively large pressure drops can be observed in the heat exchanger. The exchanger was tested in a countercurrent flow configuration with the inlet hot water having the temperature of approx. $92^{\circ} \mathrm{C}$. Figure 5 shows the thermal characteristics of the heat exchanger in the form of the rate of heat exchanged as a function of the cold water flow rate. The slope of the heat rate increases with the increase of the cold fluid flow rate. The values of the overall heat transfer coefficient are plotted in Fig. 6 as a function of the volumetric flow rate of cold water. The overall heat transfer coefficient has been calculated from the Peclet law for the heat transfer surface equal to $0.00867 \mathrm{~m}^{2}$. It should be emphasized that the total area taken for these calculations was larger than the area of $0.00694 \mathrm{~m}^{2}$ mentioned in Section 4 . The total area was calculated from the wetted perimeter of one minichannel, its length, and the number of minichannels. The area of the collectors was also taken into account, since it was about $23 \%$ of the total heat transfer area and had a great influence on the heat rate.

Figure 7 shows sample distribution of the heat transfer coefficient as a function of the logarithmic temperature difference (LMTD) for a given hot water flow rate $\left(V_{C}=350\right.$ $1 / \mathrm{h})$ and at fixed temperatures of hot water $\left(t_{C}\right)$ and cold water $\left(t_{z}\right)$ supplied at the entrance to the heat exchanger. High values of the mean logarithmic temperature difference result from the fact that the tested exchanger contained only one plate, and from high difference, of approx. $80 \mathrm{~K}$, between the heating and heated water at the entrance to the heat exchanger. In Tables 1 and 2 the values of heat transfer coefficients are tabulated.

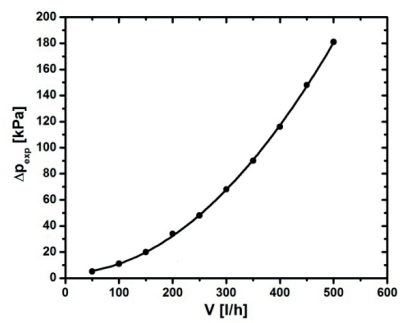

Fig. 4. Flow characteristics of the plate minichannel heat exchanger

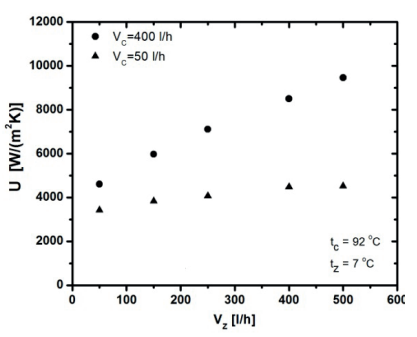

Fig. 6. Distribution of overall heat transfer coefficient vs. cold water flowrate

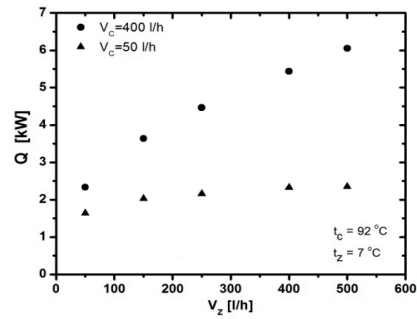

Fig. 5. Heat transfer rate $v$ s. volumetric flow of cold water

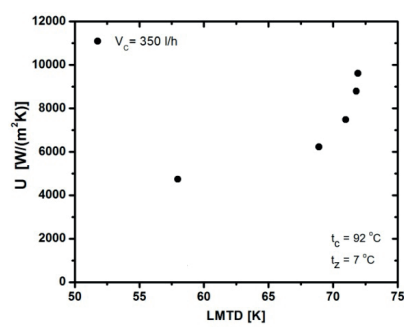

Fig. 7. Distribution of overall heat transfer coefficient vs. logarithmic mean temperature difference (LMTD) 
Table 1. Heat transfer coefficient values on the cold side of the exchanger

\begin{tabular}{|c|c|c|c|c|c|}
\hline$\dot{V}_{C}[1 / \mathrm{h}]$ & \multicolumn{5}{|c|}{$50 \div 400$} \\
\hline$\dot{V}_{Z}[1 / \mathrm{h}]$ & 50 & 150 & 250 & 400 & 500 \\
\hline$\alpha_{\mathrm{Z}}\left[\mathrm{W} / \mathrm{m}^{2} \mathrm{~K}\right]$ & 5655 & 7823 & 10017 & 12686 & 15192 \\
\hline
\end{tabular}

Table 2. Heat transfer coefficient values on the hot side of the exchanger

\begin{tabular}{|c|c|c|c|c|c|}
\hline$\dot{V}_{Z}[1 / \mathrm{h}]$ & \multicolumn{5}{|c|}{$50 \div 500$} \\
\hline$\dot{V}_{C}[1 / \mathrm{h}]$ & 50 & 150 & 250 & 350 & 400 \\
\hline$\alpha_{C}\left[\mathrm{~W} / \mathrm{m}^{2} \mathrm{~K}\right]$ & 5353 & 10222 & 12849 & 15900 & 15917 \\
\hline
\end{tabular}

The heat transfer results can be presented in the form of collective charts of heat transfer coefficient as a function of the Reynolds number for a single channel. Although the obtained experimental values refer rather to the laminar heat transfer, the data reduction relation adopted the Dittus-Boelter correlation, due to the fact that the heat transfer coefficient exhibits a dependence on the Reynolds number. However, it appears that the obtained results correlate better when the dependence of the Nusselt number on the Reynolds number is considered. The results are shown in Figs. 8 and 9. Figure 8 presents two series of experimental measurements (EXP and EXP2) and the corresponding values of the Nusselt number determined from the Dittus-Boelter correlation. The EXP and EXP2 series correspond to the cold and hot water, respectively. Some differences in the results are due to a small influence of the average value of the Prandtl number. The experimental data show higher values than those obtained from the DittusBoelter correlation. Figure 9 shows the determination of the constant which would enable to correlate the present results with the aid of the Dittus-Boelter correlation. We can see that for the Reynolds number values exceeding 700 the value of the constant is approximately 0.03 , which is higher by $20 \%$ than in the case of the original Dittus-Boelter constant $(C$ $=0.023$ ). This proves the existence of the turbulent flow at the Reynolds numbers exceeding 700 . The flow may become turbulent as a result of the existing surface roughness or sharp inlet edges of the channel.

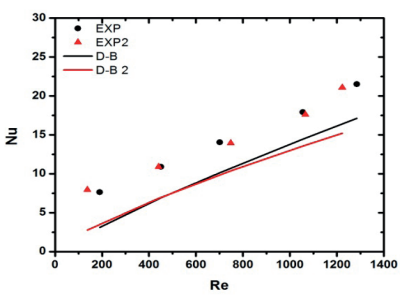

Fig. 8. Comparison of the experimental heat transfer coefficient with that determined from the Dittus-Boelter correlation

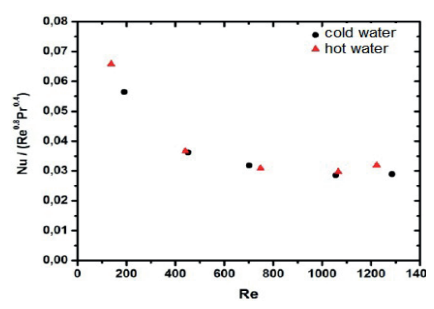

Fig. 9. Determination of the constant for modification of the DittusBoelter correlation as a function of Reynolds number. (EXP-cold water, EXP2 - hot water).

A unique finding of the study is a significant improvement of the heat transfer coefficient for the single-phase convection

of water in the channel (at least by $20 \%$ ) in relation to the values determined from the Dittus-Boelter correlation.

In the investigations of the water-water configuration, high rates of heat exchanged in the model heat exchanger have been reported. They reached $6 \mathrm{~kW}$ at the volumetric flow rates of hot and cold water equal to $400 \mathrm{l} / \mathrm{h}$ and $500 \mathrm{l} / \mathrm{h}$, respectively. What is worth emphasizing at this point is quite specific conditions of the experiment, namely high temperature difference, of approx. $80 \mathrm{~K}$, between the heating water and heated fluid at heat exchanger entrance. This was reflected in high values of the logarithmic mean temperature difference in each measurement series (values between $56 \div 75 \mathrm{~K}$ ). High efficiency of the considered heat exchangers is returned by the heat transfer coefficient, the values of which attain an approximate level of $9.6 \mathrm{~kW} /\left(\mathrm{m}^{2} \mathrm{~K}\right)$.

\section{FLOW BOILING DATA}

In case of the flow boiling data, the measurement results made the basis for determining the heat flux, $q$, LMTD, and the overall heat transfer coefficient, $U$ [11]. The overall heat transfer coefficient was determined with the aid of the Peclet's law based on the heat transfer area equal to $0.00896 \mathrm{~m}^{2}$ and the average value of the heat rate transferred through the wall in a given measurement series.

Thermal characteristics of the investigated heat exchanger are presented in Figs. 10 and 11. These figures show the transferred heat rate (Fig. 10) and the overall heat transfer coefficient (Fig. 11) as functions of the ethanol mass flux. Since the prototype minichannel PHE was designed for the purpose of heat recovery, therefore the mass flux of the heating fluid was fixed at certain levels. That is why two heating water mass fluxes, $G_{w}$, were considered (plus an additional value in some cases) for constant saturation temperature of ethanol $\left(t_{s_{-} e t}\right)$ in the heat exchanger. For higher values of the heating water mass flux, the increase was observed of the transferred heat rate and the overall heat transfer coefficient. Decreasing of the transferred rate of heat and overall heat transfer coefficient values was recorded as a response to the increase of the ethanol mass flux. This tendency resulted from a specific methodology assumed for this stage of experiment. For constant water mass flux and water inlet temperature values, the increase of the ethanol mass flux caused less intensive boiling (see Figs. 14 and 15). In such a situation, the input heat rate was not sufficient to keep the boiling at a particular level. The other reason was water boiling prevention, because of which the temperature difference between the ethanol and the water was low and equal to about 11-19 K, what influenced the entire heat transfer process.

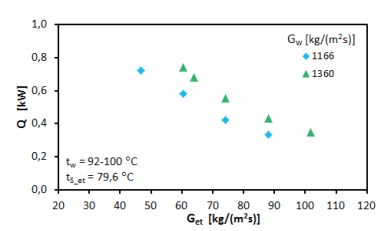

Fig. 10. Rate of heat vs. ethanol mass flux.

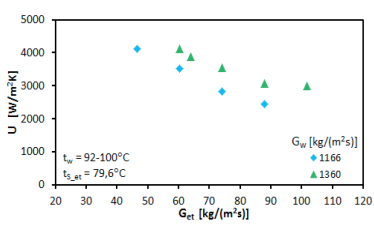

Fig. 11. Overall heat transfer coefficient vs. ethanol mass flux. 
Figures 12 and 13 present the heat flux and the overall heat transfer coefficient as functions of the logarithmic mean temperature difference ( $L M T D)$. The figures were assigned for two values of water mass flux $\left(G_{w}=1166 \mathrm{~kg} /\left(\mathrm{m}^{2} \mathrm{~s}\right)\right.$ and $G_{w}=1360$ $\left.\mathrm{kg} /\left(\mathrm{m}^{2} \mathrm{~s}\right)\right)$, and for the constant saturation temperature equal to $t_{S_{-} e t}=79.6^{\circ} \mathrm{C}$. In both cases the increase of the analysed parameters followed the increase of LMTD.

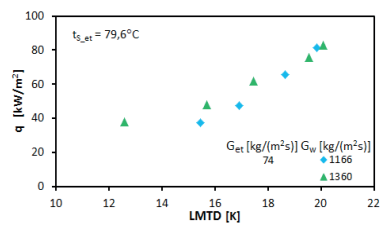

Fig. 12. Heat flux vs. LMTD.

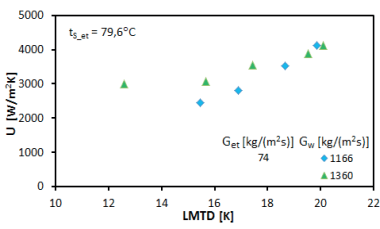

Fig. 13. Overall heat transfer coefficient vs. LMTD.
The influence of the water flow Reynolds number on the heat flux and the overall heat transfer coefficient is demonstrated in Figs. 14 and 15. Both characteristics were obtained for the ethanol mass fluxes equal to $G_{e t}=60 \mathrm{~kg} /\left(\mathrm{m}^{2} \mathrm{~s}\right)$ and $G_{e t}=74 \mathrm{~kg} /$ $\left(\mathrm{m}^{2} \mathrm{~s}\right)$, based on the Reynolds number of water flow in one minichannel defined as $\operatorname{Re}_{w_{-} 1 c h}=\left(G_{w} D_{H}\right) / \mu$, where $\mu$ is the dynamic viscosity taken from [12] for the average water temperature, $D_{H}$ is the hydraulic diameter of minichannel $\left(D_{H}=0.8235 \mathrm{~mm}\right)$ and $G_{w}$ is the mass flux described by the formula $\mathrm{G}_{\mathrm{w}}=\dot{m}_{W} / \mathrm{n} \cdot \mathrm{a} \cdot \mathrm{b}$, where $\dot{m}_{W}$ is the water mass flow rate, $n$ is the number of minichannels, and $a$ and $b$ denote the width and depth of minichannels, respectively. In both cases an increasing tendency is found.

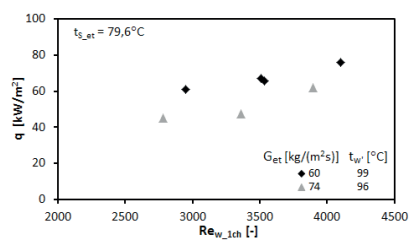

Fig. 14. Heat flux vs. water flow Reynolds number for one minichannel.

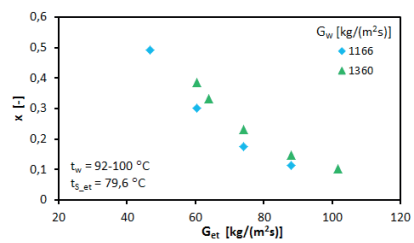

Fig. 16. Quality of ethanol vapour at heat exchanger outlet vs. ethano mass flux.

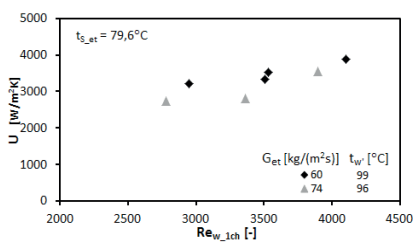

Fig. 15. Overall heat transfer coefficient vs. water flow Reynolds number for one minichannel.

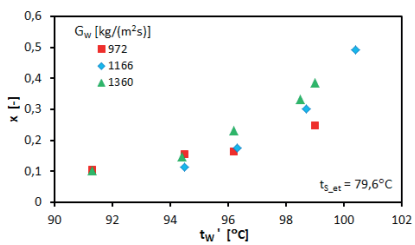

Fig. 17. Quality of ethanol vapour at heat exchanger outlet $v$ s. inlet water temperature.
The quality of ethanol vapour is the parameter which represents the intensity of heat transfer, because it depends on the boiling process and its conditions. Figures 16 and 17 show the quality of ethanol vapour as the function of the ethanol mass flux (Fig. 16) and the water inlet temperature (Fig. 17). The water mass flux and the ethanol saturation temperature were constant for the corresponding measurement series. The maximal value of ethanol vapor quality obtained in the studies was 0.5 . It was not possible to obtain higher values of quality due to the limitations described in relation to Fig. 10 and 11 . Briefly speaking, the assumption of constant water mass flux and its inlet temperature has led to the restrained input heat rate and altered the intensity of boiling. Figure 17 shows the results of an additional measurement series performed for water mass flux of $G_{w}=972 \mathrm{~kg} /\left(\mathrm{m}^{2} \mathrm{~s}\right)$ to verify the influence of as many parameters as possible.

A very useful method to determine the heat transfer coefficient value is the Wilson method [13]. However, it is mainly dedicated to single-phase heat exchangers. Principles of this method cannot be fulfilled when analysing two-phase convection, due to the variable flow rate which, according to the Wilson method, should be kept constant, for either the heating or cooling fluid. Due to boiling phenomena it was not possible to keep the ethanol flow rate constant, therefore the estimation of the heat transfer coefficients was based on the known correlations defining the Nusselt number. According to the literature [14], the application of the DittusBoelter correlation in the analysis of minichannels leads to high uncertainties. That is why the Hausen correlation was considered in the present paper as the most suitable for the considered Reynolds number range, i.e. 2300-6000. The Hausen correlation for a rectangular channel is described by following equation:

$$
\mathrm{Nu}_{w}=0.116\left(\operatorname{Re}_{w_{-} 1 c h}{ }^{2 / 3}-160\right) \operatorname{Pr}_{w}{ }^{1 / 3}\left[1+\left(\frac{D_{H}}{L}\right)^{2 / 3}\right]\left(\frac{\mu}{\mu_{w}}\right)^{0.11}
$$

where $\mathrm{Re}_{{ }_{-} 1 c h}$ is the single channel Reynolds number for water flow, $\operatorname{Pr}_{w}$ is the Prandtl number for water, $D_{H}$ is the hydraulic diameter of one minichannel, $L$ is the minichannel length, $\mu$ is the dynamic viscosity at water temperature, and $\mu_{w}$ is the dynamic viscosity at wall temperature. The necessary physical and thermal properties were taken from [12] for the water average temperature.

The calculated values of Nusselt number for the single water channel Reynolds number are presented in Fig. 18. They are followed by the calculated values of the heat transfer coefficient on the water side of the minichannels PHE, shown in Fig. 19. Both figures are shown to indicate numerical values representing the heat transfer enhancement and main parameters causing it.

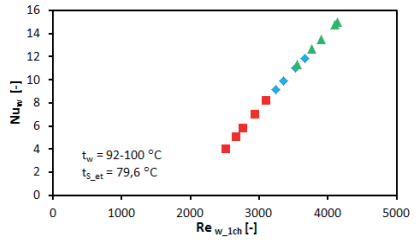

Fig. 18. Nusselt number vs. water flow Reynolds number for one minichannel.

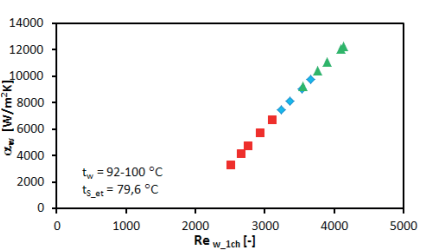

Fig. 19. Heat transfer coefficient on heat exchanger water side vs. water flow Reynolds number for one minichannel. 
The heat transfer coefficient on the ethanol side of the analysed heat exchanger was calculated from Equation (3), which took the following form:

$$
\alpha_{e t}=\left(\frac{1}{U}-\frac{\delta}{\lambda}-\frac{1}{\alpha_{w}}\right)^{-1}
$$

The calculated results are presented in Figs. 20 and 21. They show the heat transfer coefficient on the heat exchanger ethanol side as the function of the heat flux (Fig. 20), and the ethanol vapour quality (Fig. 21). The maximum value of the obtained heat transfer coefficient was about $7500 \mathrm{~W} / \mathrm{m}^{2} \mathrm{~K}$ for the ethanol side, and $12000 \mathrm{~W} / \mathrm{m}^{2} \mathrm{~K}$ for the water side. The difference in the mass fluxes should be emphasized here. The mass flux of ethanol was about 13 times lower than that of water, and the heat transfer enhancement on the ethanol side was due to boiling.

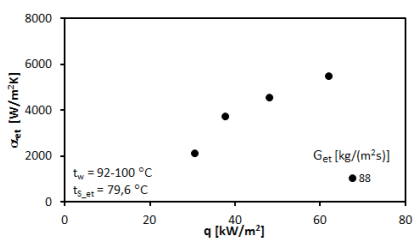

Fig. 20. Heat transfer coefficient on heat exchanger ethanol side vs. heat flux.

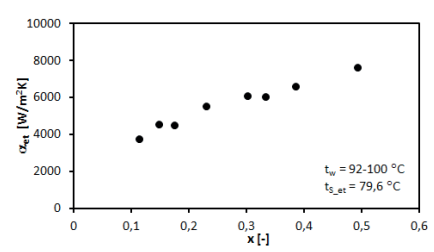

Fig. 21. Heat transfer coefficient on heat exchanger ethanol side vs. ethanol vapour quality.

\section{UNCERTAINTIES}

The uncertainty analysis of the above experimental investigations was done in a systematic manner. Taking into account the low number of measurement repetitions, but also high data repeatability, statistic uncertainties were not considered, and the uncertainty analysis focused only on systematic errors. The analysis was based on the principle of propagation of uncertainties described by the formula [15]:

$$
\Delta y=\sqrt{\left(\frac{\partial f}{\partial x_{1}} \Delta x_{1}\right)^{2}+\left(\frac{\partial f}{\partial x_{2}} \Delta x_{2}\right)^{2}+\left(\frac{\partial f}{\partial x_{3}} \Delta x_{3}\right)^{2}+\ldots}
$$

where $\Delta x$ is the maximal uncertainty of the measuring instrument. The uncertainty of the analysed functions depended on uncertainties of particular variables. In the present case, the uncertainties related to direct measurements, indirect calculations, and withdrawal of thermo-physical properties from tables. The applied uncertainties of various devices used in the experiment were described in the section discussing the experimental facility and procedure.

The results of the uncertainty analysis are summarized in Table 3. The relative uncertainty was calculated from the following equation:

$$
\delta y=\frac{\Delta y}{y} \cdot 100 \%
$$

Table 3. Summary of the uncertainty analysis

\begin{tabular}{|l|c|}
\hline \multicolumn{1}{|c|}{ Parameter } & Relative value [\%] \\
\hline mass flux & $3.4-3.8$ \\
\hline overall heat transfer coefficient & $4.7-9.0$ \\
\hline convective heat transfer coefficient (water) & $6.1-9.7$ \\
\hline convective heat transfer coefficient (ethanol) & $8.4-11.7$ \\
\hline heat rate & $4.7-9.0$ \\
\hline heat flux & $4.7-9.1$ \\
\hline Reynolds number & $3.7-4.1$ \\
\hline Nusselt number & $6.0-9.6$ \\
\hline
\end{tabular}

\section{SUMMARY AND CONCLUSIONS}

The experimental analysis of the prototype plate heat exchanger with minichannels under single-phase and flow boiling conditions of water-ethanol configuration was described. The determination of thermal performance of the heat exchanger was the main purpose of this work, therefore the thermal characteristics of the investigated unit were presented. Due to the parameters at which the boiling process was studied, the maximal value of the heat transfer rate in the considered module was at the level of $0.75 \mathrm{~kW}$ for the water and ethanol mass fluxes equal to $1166 \mathrm{~kg} /\left(\mathrm{m}^{2} \mathrm{~s}\right)$ and $47 \mathrm{~kg} /\left(\mathrm{m}^{2} \mathrm{~s}\right)$, respectively. It should be pointed out that the above results were obtained for the heat transfer area of about $0.009 \mathrm{~m}^{2}$, taking advantage from additional significant rise of hydraulic resistance generated by the initiated ethanol boiling process. Consequently, the delivery of the ethanol pump decreased. When the ethanol volume flow rate was lower, the boiling was intensified and the ethanol vapour quality increased. The highest value of the overall heat transfer coefficient was about $4200 \mathrm{~W} /\left(\mathrm{m}^{2} \mathrm{~K}\right)$, while that of the transferred heat flux was about $84 \mathrm{~kW} / \mathrm{m}^{2}$. The heat transfer coefficient values presented for the ethanol in boiling state (up to $6 \mathrm{~kW} /\left(\mathrm{m}^{2} \mathrm{~K}\right.$ ) at the heat flux of $62 \mathrm{~kW} / \mathrm{m}^{2}$, Fig. 20, have been confirmed by the fundamental investigations of ethanol boiling in minichannels [16].

In the authors' opinion, the proposed construction of the minichannel plate heat exchanger is promising. It is possible to consider other materials which would be more suitable for marine applications, as well as new manufacturing techniques which can be fully automated $[17,18]$. 


\section{BIBLIOGRAPHY}

1. Korczewski Z., Zacharewicz M.: Alternative diagnostic method applied on marine diesel engines having limited monitoring susceptibility. Transactions of the Institute of Measurement and Control, 2012, Vol. 34, No.8, pp.937-946.

2. Stolarski T.A.: Wear of water-lubricated composite materials. Wear, 1980, Vol.58, No.1, pp.103-108.

3. Jakubowski M.: Influence of pitting corrosion on fatigue and corrosion fatigue of ship and offshore structures. Part II: Load - pit crack interaction. Polish Maritime Research, 2015, Vol.22, No.3, pp.57-66.

4. Ambroziak A., Kłosowski P.: Mechanical properties for preliminary design of structures made from PVC coated fabric. Construction and Building Materials, 2014, Vol.50, pp.74-81.

5. Ambroziak A., Kłosowski P.: Mechanical properties of polyvinyl chloride-coated fabric under cyclic tests. Journal of Reinforced Plastics and Composites, 2014, Vol.33, No.3, pp.225-234.

6. Sabik A., Kreja I.: Large thermo-elastic displacement and stability FEM analysis of multilayered plates and shells. Thin-Walled Structures, 2013, Vol.71, pp.119-133.

7. Mikielewicz D., Klugmann M., Wajs J.: Flow boiling intensification in minichannels by means of mechanical flow turbulising inserts. International Journal of Thermal Sciences, 2013, Vol.65, pp.79-91.

8. Szymkiewicz A., Modelling water flow in unsaturated porous media: Accounting for nonlinear permeability and material heterogeneity, Heidelberg, Springer, 2013.

9. Wajs J., Mikielewicz D.: Effect of Surface Roughness on Thermal-hydraulic Characteristics of Plate Heat Exchanger. Key Engineering Materials, 2014, Vol.597, pp.63-74.

10. Cieśliński J.T., Mosdorf R.: Gas bubble dynamics - experiment and fractal analysis. International Journal of Heat and Mass Transfer, 2005, Vol.48, No.9, pp.1808-1818.

11. Wajs J., Mikielewicz D., Fornalik-Wajs E.: Thermal performance of a prototype plate heat exchanger with minichannels under boiling conditions. Journal of Physics Conference Series, 2016, Vol.745, 032063.

12. Refprop v.9.0 National Institute of Standards, 2010.

13. Wilson E.E.: A basis for rational design of heat transfer apparatus Trans. ASME, 1915, Vol.37, pp.47-82.
14. Adams T.M., Abdel-Khalik S.I., Jeter S.M., Qureshi Z.H.: An experimental investigation of single-phase forced convection in microchannels. International Journal of Heat and Mass Transfer, 1998, Vol.41, pp.851-857.

15. Moffat R.J.: Describing the uncertainties in experimental results. Experimental Thermal and Fluid Science, 1988, Vol.1, pp.3-17.

16. Zrooga A-B.S.R.: Experimental and theoretical study of boiling and dryout phenomenon of ethanol in vertical minitubes. (Ph.D. thesis) Gdansk University of Technology, 2010.

17. Deja M., Siemiątkowski M.S.: Feature-based generation of machining process plans for optimised parts manufacture. Journal of Intelligent Manufacturing, 2013, Vol.24, No.4, pp.831-846.

18. Szłapczyński R.: Evolutionary Planning of Safe Ship Tracks in Restricted Visibility. Journal of Navigation, 2015, Vol.68, No.1, pp.39-51.

\section{CONTACT WITH THE AUTHOR}

\section{Dariusz Mikielewicz}

Gdansk University of Technology, Faculty of Mechanical Engineering, Narutowicza 11/12, 80-233 Gdansk Poland

Jan Wajs

Gdansk University of Technology, Faculty of Mechanical Engineering, Narutowicza 11/12, 80-233 Gdansk Poland 